\title{
The Role of Water Motion in Natural Processes
}

\author{
A. D. Styrkas \\ Institute of Solid State Physics, RAS, Chernogolovka, Russia \\ Email: astyrkas@issp.ac.ru
}

How to cite this paper: Styrkas, A.D. (2017) The Role of Water Motion in Natural Processes. Journal of Materials Science and Chemical Engineering, 5, 19-32. https://doi.org/10.4236/msce.2017.54003

Received: February 5, 2017

Accepted: April 27, 2017

Published: April 30, 2017

Copyright $\odot 2017$ by author and Scientific Research Publishing Inc. This work is licensed under the Creative Commons Attribution International License (CC BY 4.0).

http://creativecommons.org/licenses/by/4.0/

\begin{abstract}
A study of the behavior of water during its movements under mechanical shaking is presented. It is shown that rhythmic shaking of water with $1 \mathrm{~Hz}$ causes the same rhythmic effects in a periodic $\left[\mathrm{H}^{+}\right]$growth and products with higher positive potential. This paper discusses the role of water motion in nature.
\end{abstract}

\section{Keywords}

Water, Mechanical Movement, Protons, Potential,

Relaxation, Nature Processes

\section{Introduction}

Water plays a major role in the natural processes. Life originated in the water of the seas with permanent shaking of waves of a frequency of about $1 \mathrm{~Hz}$. Blood is $85 \%$ water. The pulse of living organisms has the same frequency. Cardiac arrest-death certificate. Disturbance of the blood circulation causes pathologies in living organisms and its collapse causes dying and stopping of all the vital processes and functions. Similar examples of the influence of water movement are visible in almost all natural phenomena. Probably, the study of water motion provides a basis that could allow to clarify the role of the mechanical effects of water in natural processes and provide some insights for better understanding and solving of many questions, including, for example, understanding the role of the water movement has already helped to understand the ions dissociation mechanism; It helps to indicate the origin of oxygen on Earth, revealed the reason for the constancy of hydrogen peroxide in moving water. Also the formation of the products from the water, which is discussed in this paper, that yield electrical signals, could probably lead to an engineering solution of converting them into environmentally friendly sources of energy the inexhaustible energy of the Cosmos, despite their small magnitude and smallness and frequency that may be perceived as "inconvenient" from the point of view of converting and enhancing 
these signals. One could remember discoveries of Luigi Galvani and Alessandro Volta that evolved from a discovery of tiny energy source with zero frequency to the emergence and successes in modern times of power and electronics industries all over the world. Also, the findings of this paper may provide some basis for the understanding of the formation of unexplained natural vortices in superconductors that may be linked to chemical processes that may take place at the extremely low temperatures. Another example of areas where the results of this paper may provide more insights is the understanding of structured water behavior in complex living organisms under the exposure to microwave resonant therapy in medicine. Mechanics (physics) leads to the processes of transformation of water (chemistry) to substance necessary for life (biology) and global processes of the Earth (Geology).

Thus, the water behavior both in inorganic processes, as well as in living nature, confirms idea of unity laws for "living" nature ("ecosystems") and "nonliving" objects ("environment") that everything in nature is interconnected, and the division of its laws on physical, chemical, biological and geological is a consequence of our limited knowledge. The Nature is indivisible. In order to check the character of the "behavior" of water or water solution during its mechanical movement we performed measurements of Red-Ox potentials.

\section{Experiment}

The studied samples of water were water distilled and here in dissolved gases removed. The reciprocating motion of the water sample with the specified input frequency or with a relay, or the movements of the sample water volume with a time-delay switch that was made on the by means of a medical dispensrer system (the dispenser can release the required accurate portion of water for each push) that allowed to vary the frequency of the same portion of water in a still water vessel. $\Delta \mathrm{E}$ of a glass electrode $\mathrm{ESL} 48-11$, and $\Delta \mathrm{E}$ of $\mathrm{Pt}$ or $\mathrm{Pt} / \mathrm{q}-\mathrm{h}$ (q-h is quinhydrone $\mathrm{C}_{6} \mathrm{H}_{4} \mathrm{O}_{2} \cdot \mathrm{C}_{6} \mathrm{H}_{4}(\mathrm{OH})_{2}$ ) electrodes again saturated calomel (SCE) electrode by a "METEX" ME-31 voltmeter was noted manually or with H307/1 plotter continuously. Processes conducted in low ambient light. Water movement was not on electrodes comparison. Indicated electrode was shaken along with the container of water, or was fixed, but shaken by surrounded water that was washed around the electrode. The background was measured close to running engines in calm water.

Overall the experiments were conducted more than 1000 times over 10 year period. More than 10,000 curves were analyzed. Various compositions of electrodes were used, and various types of water were used, such as distilled, rainwater, melting water, tap water. These numerous experiments were conducted to establish the impact of water movement.

\section{Experimental Results and Discussion}

1. Chemical processes in the movement of water

With periodic shake of water potentials of the indicator electrodes varies with 
the same frequency [1] [2] [3]. This can't be attributed to changes in the composition of the electrical double layer of the electrode while stirring because of the lack of water foreign bodies. There is good reproducibility and freedom from the background generated by nearby electrical mechanisms. Figure 1 shows that shaking for the long-time leads to the rise of the potential of studied electrodes (from point "a") followed by its relaxation when shaking is stopped (point "b"). However, when shaking is stopped the $\Delta \mathrm{E}$ relaxes, reaching almost the initial values. Similar behavior may be observed when using any electrode. This is due to a change in concentrations of both the red-ox products as well as ions.

Red-ox products and ions are formed as result of mechanochemical process [1] [2] [3] [4]. It was noted a significant increase in $\left[\mathrm{H}^{+}\right]$by the action of the explosive waves [5]. It was also established that the creation of $\mathrm{H}_{2} \mathrm{O}_{2}$ using sonic waves (sonolise) and proposed their hypothesis of the creation in the Nature of $\mathrm{O}_{2}$ due to mechanical decay of water [6] [7] [8]. The constancy of hydrogen peroxide content in rain, rivers, oceans, regardless of the composition of the atmosphere was established [9] [10] [11].

In Figure 2, curve 1 shows the total change of potential of Pt electrode $\left(\Delta \mathrm{E}_{\Sigma}\right)$ after a single mechanical push was applied. The push forms Red-Ox products

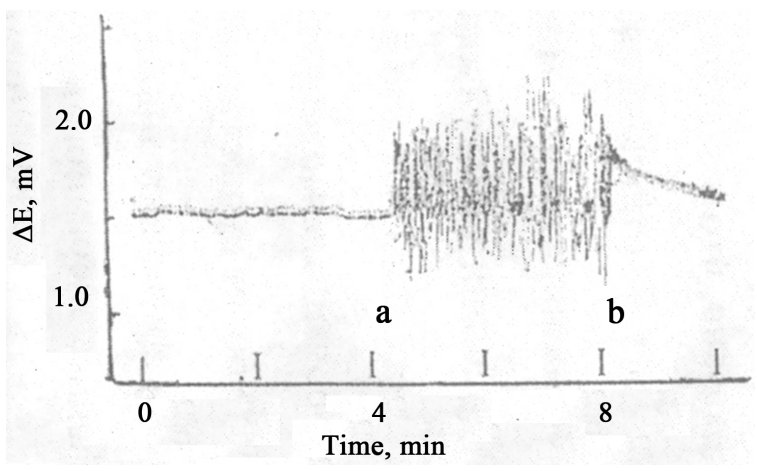

Figure 1. $\Delta \mathrm{E}$ with long-term variations (from (a) to (b)). Relaxation after the stop (b).

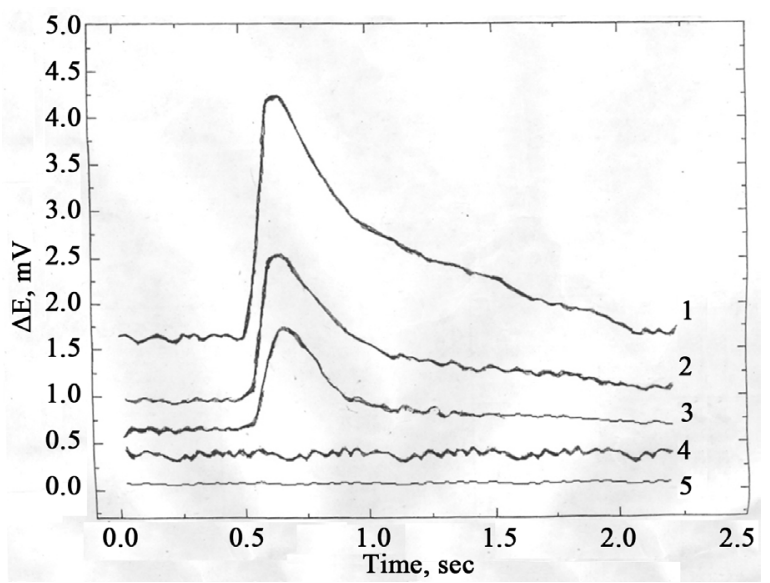

Figure 2. Effects of single mechanical push on the change of electrodes' potential $(\Delta \mathrm{E})$. Curves: 1) $\mathrm{Pt}$; 2) $\mathrm{Pt}$ at $\mathrm{pH}=3$; 3) $\mathrm{Pt}$ /quinhydrone 4) background $\mathrm{Pt}$ in clean water 5) background $\mathrm{Pt}$ in water with $\mathrm{pH}=3$ and quinhydrone. 
and ions via two ways: 1) radical way: the $\mathrm{O}-\mathrm{H}$ chemical bonds break with breaking electron pair: $\mathrm{H} \div \mathrm{O}: \mathrm{H} \rightarrow \mathrm{H}^{*}+\mathrm{OH}^{*}$ and subsequent reactions of the radicals $2 \mathrm{H}^{\star} \rightarrow \mathrm{H}_{2} ; 2 \mathrm{OH}^{\star} \rightarrow \mathrm{H}_{2} \mathrm{O}_{2} ; 2 \mathrm{H}_{2} \mathrm{O}_{2} \rightarrow 2 \mathrm{H}_{2} \mathrm{O}+\mathrm{O}_{2}$; and 2) ionic way: the $\mathrm{O}-\mathrm{H}$ chemical bonds break with the preservation of electron pair: $\mathrm{H} \mid: \mathrm{O}: \mathrm{H} \rightarrow \mathrm{H}^{+}+\mathrm{OH}^{-}$.

In Figure 2, curve 2 shows the impact on the change in potential due to reactions by the radical way $\left(\Delta \mathrm{E}^{\star}\right)$ Curve 3 shows the impact on the change in potential due to reactions by a ionic way $\left(\Delta \mathrm{E}_{\mathrm{pH}}\right)$.

In Figure 2, curves 4 and 5 show the background (no push, i.e. still water) change in potential respectively in pure still water (4) and still water at $\mathrm{pH}=3$ in aces of $\mathrm{q}-\mathrm{h}$. As seen in the figure, the ratio $\Delta \mathrm{E}_{\Sigma} / \Delta \mathrm{E}_{\mathrm{pH}} \sim 2$. In Figure $2 \Delta \mathrm{E}_{\Sigma}$ arises due to decay water on radicals and dissociation, and $\Delta \mathrm{E}_{\mathrm{pH}}$ results from the growth of $\left[\mathrm{H}^{+}\right]$at a constant ratio $[\mathrm{Ox}] /[$ Red] and therefore negligible addition of $\Delta \mathrm{E}^{\star}$ (Figure 2). Also it is observed that $\Delta \mathrm{E}^{\star}=0.5 \Delta \mathrm{E}_{\Sigma}$ when in water there is excess of acid (Figure 2, curve 3). Equality of partial $\Delta \mathrm{E}$ and their $\Sigma$ to $\Delta \mathrm{E}_{\Sigma}$ indicates that only two types of breakage of $\mathrm{O}-\mathrm{H}$ occur and that their respective energies are equal. This conclusion may also supported by the data elsewhere [5] [6] [7] [8]. The same is said NMR spectrum with one and not the two types of bonds for $\mathrm{O}-\mathrm{H}$ contrary to the view: covalent 10 times are stronger than ionic bonding, which is the case for gas $\mathrm{H}_{2} \mathrm{O}$. In liquid water has no distinction ties $\mathrm{H}$ with "his" and "alien" $\mathrm{O}($ as $\mathrm{O}-\mathrm{H} \bullet \bullet \mathrm{O})$. A gap requires equal energy. If $\Delta \mathrm{EpH} / \Delta \mathrm{E}^{*}$ $=0,1$ dissociation would be more efficient than radical formation. In water hydrogen bonds give unified energy system. The same is said NMR spectrum with 1 , not 2 types of bonds for $\mathrm{O}-\mathrm{H}$ opposing to the view that covalent 10 times stronger ionic bond, as in the case for gas molecules. Hydrogen bonds give unified energy system. Benzene has 1 type of link, and not 2, as must be at the existence of single and double bonds. $\mathrm{In} \mathrm{NH}_{4}^{+}$all $\mathrm{H}$ are identical and are arranged on the tops of a tetrahedron with $\mathrm{N}$ in the center, when gas $\mathrm{NH}_{3}$ molecule has the form of a trigonal pyramid with $\mathrm{N}$ at the top. The NMR spectrum also confirms this. Ion $\mathrm{HF}_{2}^{-}$is drawn as $\mathrm{F}-\mathrm{H}-\mathrm{F}^{-}$not $\mathrm{F}-\mathrm{H} \bullet \bullet \mathrm{F}^{-}$according to its properties and NMR spectrum. And keto-enolatautomerism is because the energetic position of the $\mathrm{H}$ atoms in the structure of the ketone or enola on bond strength is almost equal. The same substance manifests itself enole or a ketone depending on the neighboring atoms in the molecule or an external reagent.

The noise (Figure 2, curves 4 and 5) arises from the drift of the readings and temperature fluctuations. At shake water noise higher than when introduced additives, an excess of which does not see the increase in the concentration of decay products is negligible in comparison with them. The noise drift of the readings (curve 5 Figure 2) is lower than the background in curves 1 - 4. It says that impact of temperature shakes lead to dissociation, and mechanism is also due to mechanical effects.

The facts require a revision of the model water in the gas laws. For their application administered activity $a=f c$. Water has $\mathrm{f}=1, \mathrm{c}=\mathrm{const}$ and $\left[\mathrm{H}^{+}\right] .\left[\mathrm{OH}^{-}\right]$ $=10^{-14}$ for water dissociation it turns out that the fluctuations of 1 molecule will take energy $10^{7}$ other. But at small $\mathrm{kT}$ to break a connection O-H kT dissociation 
exist! The water is not molecules, but polymers, their impact $\mathrm{O}-\mathrm{H}$ ties are broken with equal energy (Figure 2) on radical pairs section e between the $\mathrm{H}$ and $\mathrm{O}$ ions and retain it at $\mathrm{O}$ refutes opinion about the difference of energy of covalent and ionic bonding in water as in the gas. In $\left(\mathrm{H}_{2} \mathrm{O}\right) n$ with $\mathrm{n}=8$ and more e- stable [12]. Analogues water $\mathrm{H}_{2} \ni$ from Teto $\mathrm{S}$ natural to decrease $\mathrm{T}$ boiling and melting sharply increase at water. Transport Number of ions of the 1st group reduced from Cs to $\mathrm{Li}$, but increases sharply to $\mathrm{H}$. "Anomalies" of different properties creates "anomalous" hydrogen bond of water. The atom 6 valence e 4 give 2 pairs of e, gives the remaining 2 valence bond with two strangers and there is ionic too. In the molecule each $\mathrm{O}$ is donor of two e pairs for unoccupied levels. One proton can bind 2 neighboring water molecules. The sizes of $\mathrm{O}$ and $\mathrm{O}-\mathrm{H}$ are small and therefore give a polymer [13]. The water is not electrostatic $\left(180^{\circ}\right)$ or valence $\left(90^{\circ}\right)$ for $\mathrm{p}$-electrons the angle between the links $\mathrm{O}-\mathrm{H}$, and is $104.5^{\circ}$. The structure of water is not chaotic (as vapor), not strictly tetrahedrically not dense pack (as ice). Short-range order is the same, but in the emptiness of the leaky lattice of secondary molecules is embedded, giving "abnormal" growth $d$ water in comparison with ice. Water is liquid glass, polymer clusters of $100 \mu$ [14] [15]. Its movement gives rise to $\mathrm{H}_{2} \mathrm{O}_{2}$. It gives Earth of $\mathrm{O}_{2}$ [1]-[8]. With a single energy cluster cracking occurs without the violation of the conservation law [16]. The energy of the collision tearing one $\mathrm{O}-\mathrm{H}$ bond, without prejudice to the cluster, though equally probable (Figure 2 ) with section a pair of electrons [1]-[8] and without it [1]-[3]. Model with a symmetrical long-range Coulomb forces is also inadequate. Theory of common electrons in the area requires introduction of "effective mass" ( $m e$ ), (as $f$ in the model gas). It is one which has (-) values for the mass and length of the free path e is smaller than the size of an atom! The lack of physical meaning of the obtained "results" is questionable in the sense of calculations by the proposed model. The model based on the number of existing bonds wiser. Pauling noted that the theoretical physicists solutions of the Schrödinger equation for any complex substances for such a long period there is no, so we have to use reliable structural chemical representations [17].

2. Physical processes in the movement of water

M. Folmer [18] said: "In contrast to the biological analogy in the formation of crystalline embryos is "spontaneous". Is this true? For example, water, whose polymers are exposed to the structure of the boundary phases, consider the formation/growth of new phases in water/ice system. Believed that ice is slippery by pressure melts. But ice is slippery at low $\mathrm{T}$, when the pressure is not enough for melting, so a layer of water on the ice surface always exists [19]. Surface structure is different from bulk. At the movement processes and changes in the structure of the clusters are active on the phase boundary. Structures and effects on them depend on external substances. The "tin plague" comes at the germ is isomorphic to [20] aSn, InSb, CdTe. Infection at a distance [21] [22] is possible, as by contact with an inert substance, earlier contacted the seed [23], infects only in the presence of water vapor. [24]. In a vacuum no infection even with a contact the seed to the tin by "crocodile", so Sn covered with a layer of oxide. Stable 
below $-120^{\circ} \mathrm{C} \mathrm{I}{ }_{c}$ is isomorphic with the structure of $\alpha \mathrm{Sn}$ and equal a lattice, epitaxial gives the seed in nano quantities, is able to reach the surface of the tin through nano-defects in the SnO due to the size of water molecules. Nano quantities do not allow to undergo the phase transformation to ordinal water at room $\mathrm{T}$ [24]. Treatment by matter, the solvent of the Ic, remove it in the desiccator or vacuum, infection doesn't. It is natural to expect inability of infection under the water. But it happens after $\sim 1$ year, but only with shaking. Water is formed an epitaxial structure the seed. The Sn when infected behind the germs, gives a polycrystalline powder. But rare in water I gives a small number of embryos, and rate of growth above the rate form of new. From any crystals $\beta$ Sn (Figure 3(a)). One germ causes the growth of only single crystal aSn (Figure 3(b)). To grow the single crystal $\alpha \mathrm{Sn}$ from the $\beta S \mathrm{~S}$ single crystals of different orientation was not possible. [22], growing under water do it [25] [26] (Figure 3(b), left side). Ultrasound reduces the time of infection under the water from $\sim 1$ year to some minute, so the abundance of embryos gives the powder $\alpha \mathrm{Sn}$.

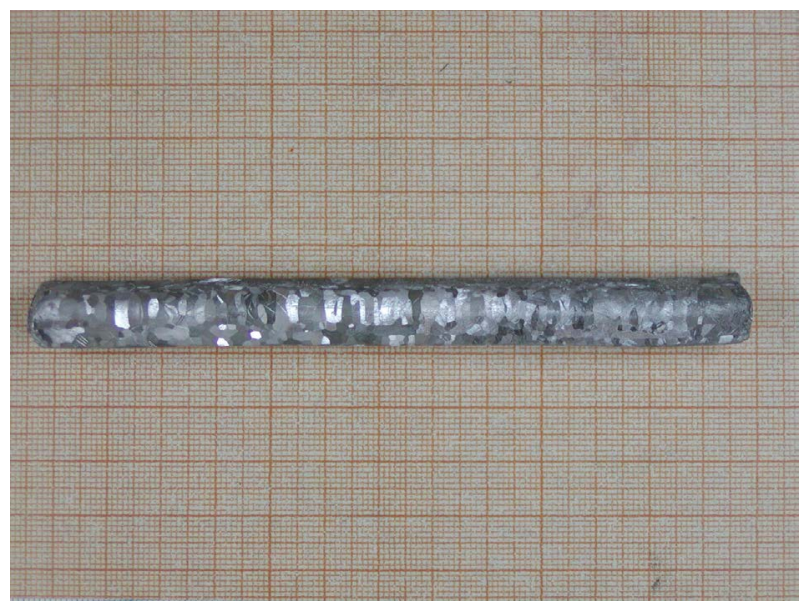

(a)

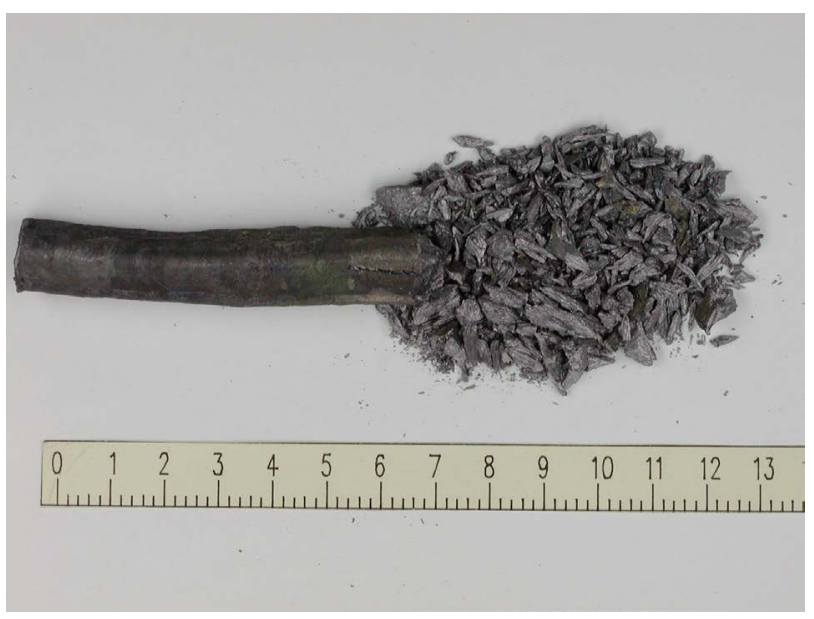

(b)

Figure 3. (a) polycrystal $\beta \mathrm{Sn}$; (b) left half of the same sample under ice became a monocrystal $\alpha \mathrm{Sn}$. Then ice was removed and the remaining part of the sample form became polycrystal of $\alpha \mathrm{Sn}$ (B, right half). 
The structure of water and its ability to change with shaking lead to other "Anomalies". Transport number (TN) of electricity in solutions of ions is due to the structure of the polymers of water. TN ions decrease with their size owing to the growth of hydration from $\mathrm{Cs}$ to $\mathrm{Li}$, but increase sharply at $\mathrm{H}$ because it does not moves through the solution. When a mobile integrated power system of the excited electron increases "mobility" of remaining in the place of protons, the structure with no long-range order constantly changes. On the surface the lifetime of structures are more than in volume, and they are influenced by boundary material. The ice surface is covered with a thin water slide. At low $\mathrm{T}$ not caused by the phase transition from pressure. Snowflakes grow in hexagonal symmetric particles of different shapes. They come in contact with dust particles of various nature and other different factors. Type embryos depend on them, but each germ is formed according to its program, and all rays are the same of crystalline at each snowflake due to the mobility of the water clusters at surface when driving their changing structures.

3. Biological processes in the movement of water

Engels said: "Life is the mode of existence protein bodies". The jellyfish is $95 \%$ of water, proteins, fats, carbohydrates, salts-where? The herbs, trees, vegetables, and fruits generally have no protein. So they are inanimate? Every life form requires water. The constancy of $\mathrm{H}_{2} \mathrm{O}_{2}$ in moving water due to reactions of water, not the absorption of $\mathrm{O}_{2}$ depleted atmosphere for them [9] [10] [11]. Conversely, when vibrations arise, these substances are essential to life. An environmental disaster occurs when the oil spills in the "calming" waves, and stops supplies from vibrations. The water is not filled up by them, and fish are dying without them. Rain gives the plants the necessary substances and building material in the form of polymers with defects. The expression "Grow like mushrooms after rain" perceives that mushrooms just need in the water. But the mushrooms living in the rich wet soil of swamps after the rain grow harder. They need not only water, but moving, rich need for life products. Idea that life is the existence of proteins, is ridiculous, because most of the plants are "outside". Life originated in the sea. Wave vibrations with a frequency of $1 \mathrm{~Hz}$ and pulse beings $\sim 1 \mathrm{~Hz}$, it is hardly by chance similar. And the name of the creator of the unit of frequency is the Heart! Coincidence eloquent. "The life-movement is animated water" (Leonardo da Vinci) Almost word for word: life-movement of structured water. Death during cardiac arrest, i.e., cessation of blood flow, which is structured of water.

Capillaries provide the system for blood circulation within a living organism. Blood consists of is $80 \%$ of water. There are about 2000 capillaries in a $1 \mathrm{~mm}^{3}$ of a skeletal muscle of a human and blood, passing through them, comes in contact with $0.5 \mathrm{~m}^{2}$ of surface of their internal walls. The surfaces properties of water are different from the volume ones. For example there is a thin layer of water on the interface of ice with other phases [19]. The $\tau$ (lifetime) of the structural form of water in thin surface layers can substantially exceed that in the bulk. A similar example of the role of water in physics-the possible to initiate transformation 
$\beta S n \rightarrow \alpha$ Sn [27] under water.

The clusters are in the current of the water a variety of forms, but their restructuring is going in the specified direction in the presence of external bodies, for example, biological substances, including midget doses. This is based on the homeopathy. Molecules of substances surround the polymers of the water, adapting to their structure, so in the absence of them reproduce the therapeutic effects.

Peculiarities of structure of water and its behavior under weak mechanical movement in inorganic systems could be used for explanation of processes in complex living organisms, to understand efficiency of medical treatment by means of weak energy influence. The low level of power of EM radiation of $\mathrm{mm}$ range, the influence on an organism in process microwave resonant therapy (MRT) is effective and enough. The system of the blood circulation in the organism with a developed capillary surface provides existence of preferential directions for protons motion along chains of hydrogen bonds in the thin surface layers of water. Pathologic processes in an organism appear because of the disturbance of proton conductivity in capillaries. It is possible that quantities of energy necessary for their recover may be negligible in comparison with the potential barrier between two equilibrium positions of a proton in the chain. Weak fields affect the properties of the membranes, the processes in cells, to long-range interaction communication functions of the system organisms. Water with great speed betrays the signal of injury and external influences in the system of decision-making for restoration of violations. The mobile network of hydrogen bonds provides the speed and action at a distance in the transmission of information. Energy for the recovery of self-consistent vibrations in the H-bonds system (and, consequently, for process of metabolism) is not necessary at all. The channels of proton conductivity provide long-distance action because of the soliton mechanism [28] of energy migration. It is probable that energy in released in locations of damages of the ordered networks of the H-bonds, and recovers them. These weak influences can't change the character of $\mathrm{H}$-bonds in a correctly functioning structure of near-surface water. It should be mentioned that the blood capillaries characteristic for skin, skeletal muscles, muscular system, heart, cerebrum, i.e. organs functions of providing contact with external are the same.

In conclusion, that is a simple experiment illustrating the role of water movement on the example of the growth of Kalanchoe in the same 2 Petri dish with the same amount of soil from turf and peat soil and sand in the ratio 2:1:1. They put some of the same kidney with the roots in winter, at ambient light. Water from melting snow to the control (2) thermostated at $18^{\circ} \mathrm{C}$, and experience (1) at $17.9^{\circ} \mathrm{C}$ so irrigation water was the same $\mathrm{T}$. (water is heated at $0.1^{\circ}$ in the preparation of water) Water for (1) 30 min pumped with a positive displacement pump, gaining $10 \mathrm{ml}$ of water from the vessel and introducing her back with a frequency of $1 \mathrm{~Hz}$. To kidney (1) was water after oscillations, and (2) simple water. Portions of $20 \mathrm{ml}$ water the kidneys once every 3 days, after 3 weeks experience was finished. The effects of the mechanochemical processes in water can 
be seen from Figure 4 and Figure 5. Thus, the water behavior both in inorganic processes, as well as in living nature, confirms idea of unity laws for "living" nature and "non-aliving" objects ("environment").

4. Geological processes in the movement of water

V. I. Vernadsky called the mineral water as a creator of landscape and processes on the planet. Movement of water to create products that affect the physical properties, gives life, heals, nurtures, creates geological masterpieces, mountains and continents, and mighty rivers in the rocks, the threat of a tsunami, move the continents, currents that regulate the planet's climate. The role of water and its movement in geological processes is huge. In [9] [10] [11] observed the constancy of the $\mathrm{H}_{2} \mathrm{O}_{2}$ content in rain waters from different areas of the US with all sorts of atmospheric composition with significant differences in content

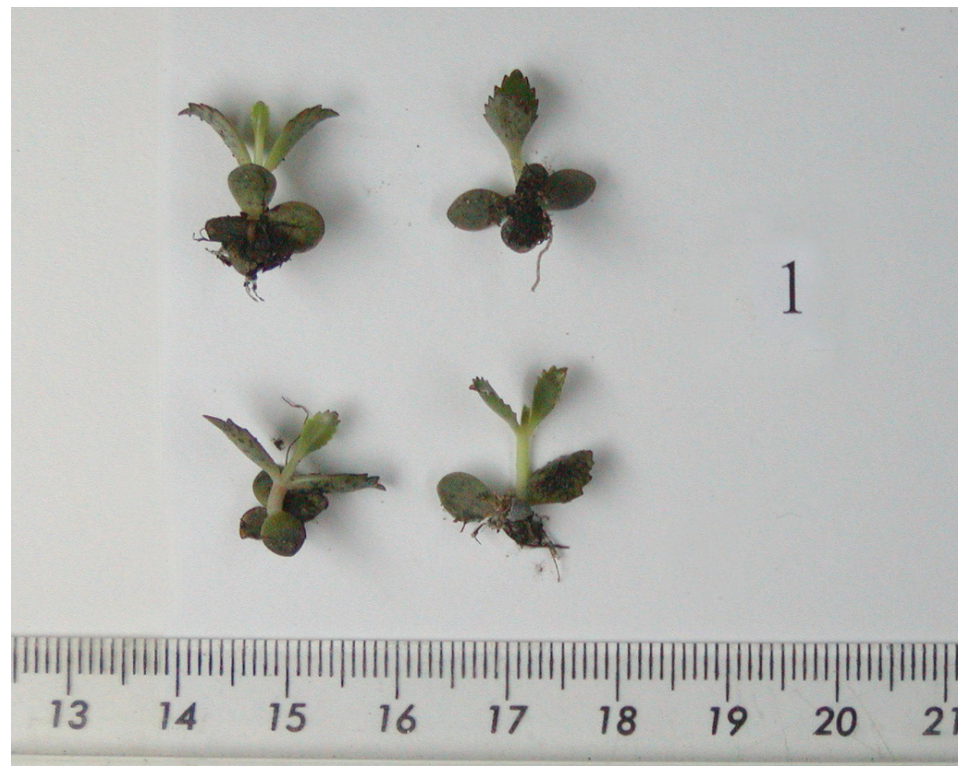

Figure 4. Buds (1) visible formed new leaves (shaking of water leads to the growth of plants).

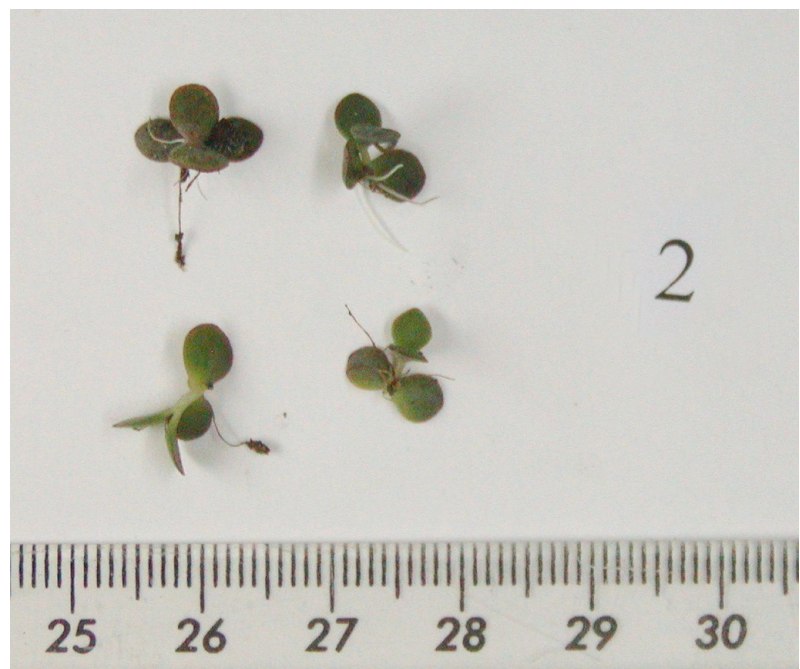

Figure 5. Buds (2) of Kalanchoe-control experience. Water without shaking. 
of oxides of S and N. Believed that shake of water in the clouds leads to the dissolution of $\mathrm{O}_{2}$ from atmosphere (however, lower concentrations than at the surface!) and the formation of peroxide. It is proved that the mechanochemical decomposition of water with a gap of a pair of electrons $\mathrm{H}: \mathrm{O} \div \mathrm{H}$ gives the radicals $\mathrm{OH}^{*}$ and $\mathrm{H}^{*}$ that give the peroxide, the excess is decomposed, giving $\mathrm{O}_{2}$ to the Earth, $\mathrm{H}_{2}$ upper layers of the atmosphere. On the Earth has not dried up $\mathrm{O}_{2}$ due to the energy of the Cosmos, constantly influencing to the movement of water. Idea [6] [7] [8] about the abiogenic emergence of $\mathrm{O}_{2}$ on the Earth due to the movement of water is more and more evidence, and direct evidence of the formation of gases $\mathrm{H}_{2}$ and $\mathrm{O}_{2}$ [4] removed the last doubts. Probably, in case of a spill on water oil the fish dies because oil calms the sea, continuing education is necessary for life substances. In the beginning the Earth was not them. When icing the stationary ice does not allow them to appear. This conjecture has opponents. Exact origin of water on our planet, covering $71 \%$ of the surface is still a mystery to science. Suspect that the water of the Earth for 4.5 billion years would evaporate, the water came later, when massive celestial bodies of the Solar system fell to the Earth. Perhaps they had the water (but why it there wasn't evaporated?), could deliver it to us. Comets with tails of ice did it too. But here a trouble: in their water more of deuterium! The Earth's water is not from them, but our own, Earthly Nature. Space is full of $\mathrm{H}_{2}$, it is in the formation of hot celestial bodies reacts with all other elements, and $\mathrm{O}_{2}$ couldn't remain at high temperatures and an excess of $\mathrm{H}_{2}$. During the cooling of the planet's water is frozen and ice as light substance covered the surface of the Earth. But the core processes of Land given to volcanoes with the content of gases-oxides of C, S, N. They created a layer of the atmosphere called the greenhouse effect, the ice was melting, and shakes of water were given oxygen and, therefore, the life. Plants create from carbon dioxide and water, but by him for the appearance had needed oxygen. Usually think of $\mathrm{O}_{2}$ on Earth is the product of photosynthesis. Process $\mathrm{nCO}_{2}+\mathrm{nH}_{2} \mathrm{O}=\mathrm{n}\left(\mathrm{CH}_{2} \mathrm{O}\right)+\mathrm{nO}_{2}$ possible in the warm time of the year, on day and if there are plants. The water of the oceans is $71 \%$ of the Earth's surface and ranges round always at any time of the year. Always added by the same movement of water in clouds, rivers, waterfalls, avalanches. Of the $29 \%$ of land plants are not suitable glaciers, rock, deserts. For the remaining $15 \%$ is photosynthesis only during the day and only in the warm time of the year, in 4 more times, reducing the opportunity. Photosynthesis increases the content locally, without raising it in the end. Avalanches of ice also give rise to $\mathrm{O}_{2}$. From the friction of the ice in the spring ice drifts, the air is richer with oxygen, ozone. We all know how much easier it is to breathe near waterfalls, fountains, on the embankments of the rivers and seas. The plants are not eternal. When they decay, the reaction goes exactly the opposite, without changing anything in total. The role of photosynthesis is large, but it is not necessary to ascribe to other merits.

Mobile water wilts to the depths of the Earth, and the reactions with hot carbides giving us the oil, as demonstrated by Mendeleev. The usual theory of oil from dead plants is questionable. The depth of oil is high and it is difficult to 
imagine lungs of the plants got there. The richness of oil by sulfur compounds, which are not plants, said the weakness of traditional theories. Processes of volcanic eruptions, earthquakes associated with the chemical processes between water and hot in the bowels of Earth substances. Water is creator of geological processes. Displacements, disappearances or appearances of continents, Islands speak about the role of moving water. Due to the motion of the water, there is a unique Sargasso sea without shores with a high level of water. Soft water breaking the rocks, created the mighty Niagara falls and the Grand canyon of Colorado. What does tsunami! Museums of natural beauty are created by the water movement under the name "Karst phenomena". Surprising similarities are located on different sides of the Earth Australia and Greenland. In the mid of Australia there is a desert without vegetation and greens; in Greenland, a desolate glacier is in the center and greens are around the edges, which gave the name to the continent. Only water movement was spared, and its absence leads to the death of all living things. Archaeology says that the Sahara desert was blooming with a mild climate and there was water. The desert was the result of man-made disaster. Now Aral sea disappeared, disappearing marshes and rivers, changing their directions, and creating seas. The Nature grew "assistant". In Sukhumi monkeys nursery among the rich subtropical vegetation was the land plot. To monkey were given freedom, democracy, individual rights. So there is not one leaf of grass was hurt, is already a formed polished bare soil. Reminiscent of what makes progress with the water, flora, fauna,the atmosphere, our environment. It is hoped that Nature will repent its child, Homo sapiens, and the movement of water will keep $\mathrm{O}_{2}$ from destruction by vehicles, furnaces and thermal power plants.

\section{Conclusions}

This paper has studied the processes of water molecules breakdown, which seemed to be impossible, as the result of mechanical exposure. A mechanism of these processes is proposed that is analogous to the mechanical cracking that occurs during the destruction of polymers.

It has been demonstrated the equality, and not radical differences, of energies of covalent and ionic bonds between $\mathrm{O}$ and $\mathrm{H}$ resulting from equalizing of all bonds in the condensed phase that is facilitated by hydrogen bonds in water molecular clusters.

This contests the sustained opinion of their differences, as this takes place in gases. The energy of water clusters due to hydrogen bonds is significantly larger than the energy of $\mathrm{O}-\mathrm{H}$ and the formation of radicals does not contradict the law of the conservation of energy. Collisions of water clusters break chemical bonds in liquids and solids, and form radicals, ions. Liquid water is considered as a "perfect set of anomalies". It is the hydrogen bonds that are responsible for this.

Hydrogen bonds equalise all $\mathrm{O}-\mathrm{H}$ bonds, which have different strength in gases with individual molecules, and these bonds break with equal probability, and not as covalent and ionic bonds. In water covalent and ionic bonds are 
equal. Water anomalies cannot be explained by laws that are applicable to gases and crystals. New ways should be sought to model and explain the water anomalies, e.g. models of glass or polymers. A role of other substances is shown to be impacting the formation metastable structures, which exist for prolonged time under such impact. In organisms, that consist of $70 \%$ to $90 \%$ of water clusters (water polymers), such polymers exist in their respective structures. The "fragments" of water polymers adjust to them helping the organisms to grow. The moving water yields products of chemical reactions and builds structures analogous the matrices of foreign inclusions, impacting physical, chemical, biological and geological processes. Water, which has the leading role for lives on Earth, also helps sciences. The process of water dissociation into ions is now explained as resulting from the motion of water. The mechanism of water dissociation is explained. The origin of oxygen on Earth is also explained as a result of mechanochemical processes and not for photosynthesis, which has crucial significance.

In Nature everything is interlinked and the division of natural philosophy into separate sciences only manifests the limitation of our current knowledge. Mechanics (physics) leads to the conversion processes in water (chemistry) into substances, which are vital for lives (biology) and global processes of Earth (geology). Thus, the water behaviour both in inorganic processes, as well as in living nature, confirms idea of unity laws for "living" nature ("ecosystems") and "nonliving" objects ("environment"). In summary, it has been:

1. Shown the equality of the energies of all of the links $\mathrm{O}-\mathrm{H}$ in liquid water.

2. Explained the reason for the existence of electrolytic dissociation.

3. Confirmed the idea of the biogenic origin of $\mathrm{O}_{2}$ and the role of water movement in this process.

4. Shown the positive role of the water movement on the development of plants.

5. Explained the reason for the constancy of the peroxide in the moving water.

\section{Acknowledgements}

Author is grateful for useful advices, discussion of results, made remarks and displayed interest to the work to unforgettable N. G. Nikishina.

\section{References}

[1] Nikishina, N.G., Rud'ko, B.F. and Styrkas, A.D. (2005) Dynamics of Redox Processes in Moving Water and Some of the Issues of Quantum Medicine. Phys. of Alive, 13, 82-94. (In Russian)

[2] Styrkas, A.D. and Nikishina, N.G. (2007) Mechanochemical Processes in the Water. High Energy Chemistry, 41, 452-459. (In Russian) https://doi.org/10.1134/S0018143907060021

[3] Styrkas, A.D. and Nikishina, N.G. (2009) Chemical Processes in Water as It Moves. Russian Journal of Inorganic Chemistry, 54, 1025-1031. (In Russian)

[4] Styrkas, A.D. (2011) The Study of the Composition of Gas Products Formed during Oscillatory Movements of Water. Russian Journal of Inorganic Chemistry, 56, 1092 - 
1094. (In Russian)

[5] Anan'in, A.V., Bavina, T.V., Breusov, O.N. and Pershin, S.V. (1975) Redox Processes under Shock Loading of Water Solutions. DAN USSR, 222, 845-847. (In Russian)

[6] Domrachev, G.A. and Selivanovsky, D.A. (1990) The Role of Sound and Liquid Water as Dynamically Unstable Polymer System in a Non-Biogenic Origin of Oxygen and the Origin of Life on Earth. Preprint No. 1, Gorky: IMC of the USSR, 19S. (In Russian)

[7] Domrachev, G.A. and Rodygin, L. (1992) The Role of Sound and Liquid Water as Dynamically Unstable Polymer System in the Mechanical Activated Processes to the Production of Oxygen in the Earth. Journal of Physical Chemistry, 3, 851-855.

[8] Domrachev, G.A., Rodygin, Y.J.L. and Selivanovsky, D.A. (1993) Mechanochemical Activated Decomposition of Water in Liquid Phase/DAN USSR, Physical Chemistry. 186-188. (In Russian)

[9] Chameides, W.L. and Davis, D.D. (1982) The Free Radical Chemistry of Cloud Droplets and Its Impact upon the Composition of Rain. Journal of Geophysical Research, 87, 4863-4877. https://doi.org/10.1029/JC087iC07p04863

[10] Zika, R.G., Saltzman, E.S., Chameides, W.L. and Davis, D.D. (1982) Journal of Geophysical Research, 87, 5015-5017.

[11] Chameides, W.J. and Zika, R.G. (1983) Photochemical Formation of Hydrogen Peroxide in Surface and Ground Waters Exposed to Sunlight. Science, 220, 711. https://doi.org/10.1126/science.220.4598.711

[12] Novakovskaya, Y.V. and Stepanov, H.F. (2000) Hydrated Electron AB Initio Modeling. The Journal of Physical Chemistry, 74, 71-79. (In Russian)

[13] Bernal, D. and Fowler, R. (1934) The Structure of Water and Ionic Solutions. Success Phys. Sc., 14, 1312-1324. (In Russian)

[14] Smirnov, A.N. and Syroeshkin, A.V. (2004) Supramolekulyar Complexes of Water. Russ. Chem. J., 48, 125-135. (In Russian)

[15] Smirnov, A.N., Lapshin, V., Balashev, A.B., et al. (2005) Water Structure Giant Heterophase Clusters of Water. Chemistry and Technology of Water, No. 2, 11-37. (In Russian)

[16] Fomin, V.N. (2004) The Impact of Mechanical Treatment on the Formation of Properties of Multicomponent Systems. Science, 82. (In Russian)

[17] Pauling, L. (1960) The Nature of Chemical Bond. 3rd Edition, Cornell University Press, New York, 220 p.

[18] Folmer, M. (1986) The Kinetics of New Phase Formation. Nauka, Moscow, 208 p.

[19] Hobbs, P.V. (1974) Ice Physics. Clarendon Press, Oxford, 352 p.

[20] Goryunova, N.A. (1950) To the Question of $\beta$ - $\alpha$ Transformation of Tin. DAN of the USSR, 75, 51-54.

[21] Kuo, K. and Burgers, W.G. (1956) An X-Ray Investigation of the White to Grey Transformation of Tin. Proceedings of the Koninklijke Nederlandse Akademie van Wetenschappen (Amsterdam), 59B, 288-297.

[22] Aptecar, I.L. and Styrkas, A.D. (1982) Contamination of Tin in the Distance. DAN of USSR, 265, 1155-1157.

[23] Aptecar, I.L. and Styrkas, A.D. (1993) Inert Substrate Like Vectors Tin Plague from in Sb for Sn. High-Purity Substances, No. 3, S56-S60.

[24] Aptecar, I.L. and Styrkas, A.D. (1987) $\mathrm{H}_{2} \mathrm{O}-$ The Causative Agent of Plague Tin. 
DAN USSR, 297, 1149-1151.

[25] Styrkas, A.D. (2003) The Grow Crystals of Gray Tin. Inorganic Materials, 39, 808811. (In Russian) https://doi.org/10.1023/A:1024527523260

[26] Styrkas, A.D. (2016) Life, Memory, Recognition and Aging of Grey Tin. Journal of Materials Science and Chemical Engineering, 4, 1-11. https://doi.org/10.4236/msce.2016.411001

[27] Styrkas, A.D. (2003) Infection of Tin in Liquid Water. Inorganic Materials, 39, 940 943. (In Russian)

[28] Davydov, A.S. (1984) Solitons in Molecular Systems. Naukova Dumka, Kyiv, 208 p. (In Russian)

Submit or recommend next manuscript to SCIRP and we will provide best service for you:

Accepting pre-submission inquiries through Email, Facebook, LinkedIn, Twitter, etc. A wide selection of journals (inclusive of 9 subjects, more than 200 journals)

Providing 24-hour high-quality service

User-friendly online submission system

Fair and swift peer-review system

Efficient typesetting and proofreading procedure

Display of the result of downloads and visits, as well as the number of cited articles Maximum dissemination of your research work

Submit your manuscript at: http://papersubmission.scirp.org/

Or contact msce@scirp.org 